\title{
The Size and Morphological Study of Spherical Polyelectrolyte Complex Beads Using Environmental Scanning Electron Microscopy.
}

\author{
V. Neděla ${ }^{1}$, M. Bučko ${ }^{2}$, E. Tihlař́́ková ${ }^{1}$, T. Krajčovič ${ }^{2}$, P. Gemeiner ${ }^{2}$ \\ 1 Environmental electron microscopy group, Institute of Scientific Instruments of ASCR, \\ Královopolská 147, 61264 Brno, Czech Republic \\ 2 Institute of Chemistry, Centre for Glycomics, Slovak Academy of Sciences, Dúbravská cesta 9, \\ 84538 Bratislava, Slovakia
}

Development of new polyelectrolyte complex (PEC) capsules/beads for biotechnological applications such as the immunoisolation of Langerhans islets for the treatment of diabetes and the stabilization and reuse of enzymes and bacterial cells as biocatalysts is very important [1]. Morphological characterization and study of PEC beads properties represents important challenge for electron microscopy. These very beam-sensitive bio-polymer capsules used for immobilization of cells are laboratory produced as a uniform with a controlled shape, size, membrane thickness, permeability and mechanical resistance [1]. Owing to importance to study above mentioned parameters, samples must be inspected in their fully native and functional state. It means free of freezing, chemical contamination or preparation, shape distortion and in thermodynamically stabile and fully wet state, precisely reached after very slow changing of conditions in the specimen chamber of ESEM. Violation of these conditions leads to deformation and burst of thin semipermeable membrane surrounding liquid core, containing live bacterial cells, for example E. coli. The aim of this work is to prove ability to use our non-commercial ESEM AQUASEM II for inspection and developmental support of this type of samples and demonstrate their sensitivity on two types of PEC beads prepared from alternative materials.

PEC beads has been produced by air-stripping nozzle via polyelectrolyte complexation (20 min) of sodium alginate and cellulose sulphate (CS) as polyanions, poly(methylene-co-guanidine) as a polycation, $\mathrm{CaCl}_{2}$ as a gelling agent and $\mathrm{NaCl}$ as an antigelling agent [1] without the use of a multiloop reactor. Two different sources of CS have been tested for preparation of PEC beads (CS from Across Organics, N.J., USA; Fig. 1) and alternative PEC beads (tailor-made CS from Senova, Weimar, Germany; Fig 2). Due to the relatively big size of samples $(800 \mu \mathrm{m}$ in diameter) and their beam sensitivity, a combination of our newly published method [2] and special improvement of our ionization detector of SE were used. The gentle and slow sample chamber pumping procedure [2] and our ionization detector of SEs [3] (beam current up to $40 \mathrm{pA})$ enhanced for larger field of view $(850 \mu \mathrm{m})$ were combined. Samples were observed in small droplet (approximately $10 \mu \mathrm{l}$ ) of distilled water. Both types of matrices were observed at sample to second pressure limiting aperture distance $4 \mathrm{~mm}$. For thermodynamic equilibrium adjustment control, Pfeiffer pressure gauges CMR 261 and CMR 263, a custom build Peltier stage and a hydration system were used.

Fully wet and well preserved membrane free PEC beads with visible surface microstructure are presented in Fig. 1B and Fig. 2B. Especially PEC beads made from alternative material, see Fig. 2 are very sensitive to beam and environmental impact. The extent of sample damages due to ESEM observation can be evaluated by the juxtaposition of images from the light microscope (Figs.1A, 2A) and ESEM (Figs.1B, 2B). Long-term effect of primary electron beam impact on the sample is obvious in Figs. $1 \mathrm{C}$ and 2C. Sample shrinkage throughout the volume, see Fig. 2C, or deformation of the outer spherical segment, see Fig. $1 \mathrm{C}$ is evident. New methods for study of PEC beads at lower beam 
accelerating voltage ( $3 \mathrm{keV})$, beam current bellow $20 \mathrm{pA}$ and using new detection systems are in process of our research. Acknowledgments go the grants [4].
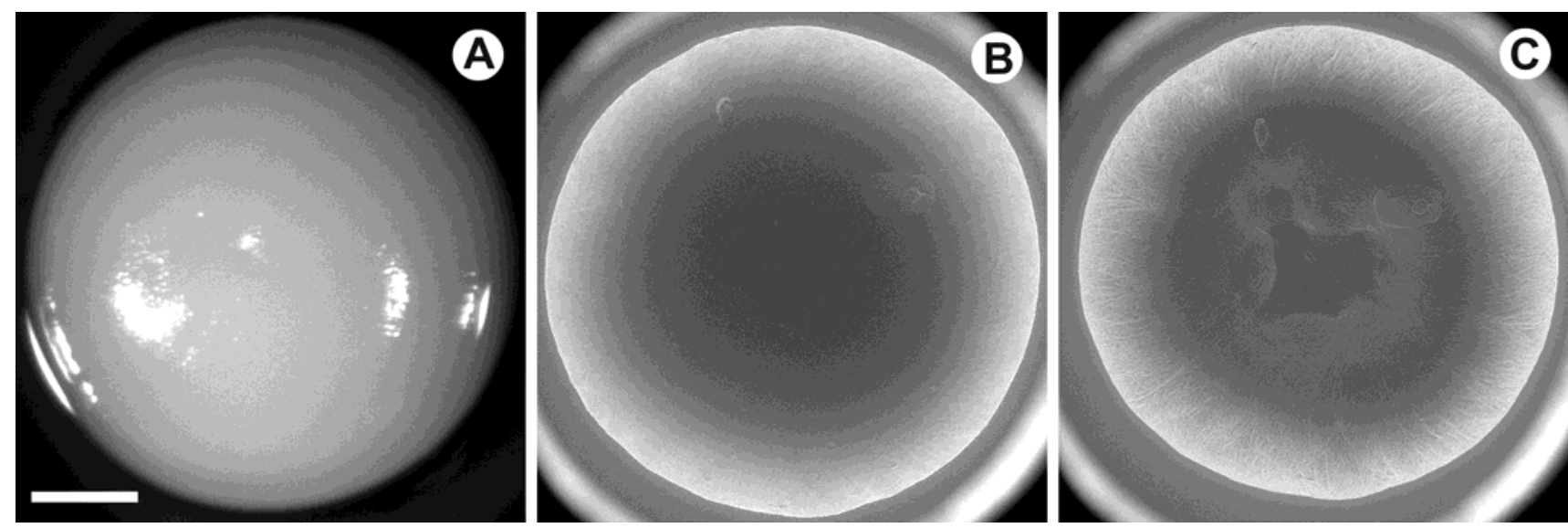

Figure 1: PEC beads with immobilized recombinant cells E. coli (10\% of wet cells) overproducing enzyme cyclopentanone monooxygenase. A) light microscope; B) AQUASEM II, ionization detector, acc. voltage $20 \mathrm{kV}, 4 \mathrm{~min}$. from start of observation, beam current $35 \mathrm{pA}$, vapor pressure $684 \mathrm{~Pa}$, stage temperature $2{ }^{\circ} \mathrm{C}$, humidity $97 \%$. C) the same as B but $12 \mathrm{~min}$. from start of observation, vapor pressure $671 \mathrm{~Pa}$, humidity $95 \%$. Bar is $200 \mu \mathrm{m}$.
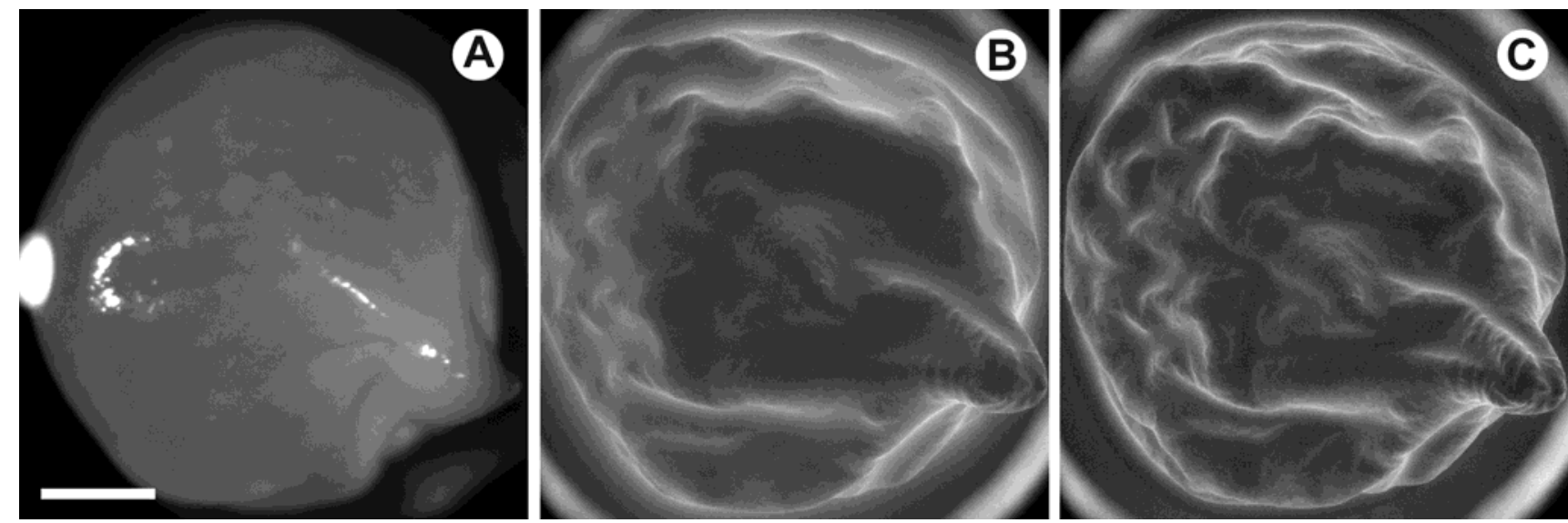

Figure 2: Alternative PEC beads prepared using tailor-made CS with immobilized recombinant cells $E$. coli (10\% of wet cells) overproducing enzyme cyclopentanone monooxygenase. PEC beads compared to Fig.1 (more beam and environmental sensitive material). A) light microscope; B) ESEM AQUASEM II, ionization detector, acc. voltage $20 \mathrm{kV}, 4$ min. from start of observation, beam current $35 \mathrm{pA}$, vapor pressure $661 \mathrm{~Pa}$, stage temperature $2^{\circ} \mathrm{C}$, humidity 94\%. C) the same as B but $12 \mathrm{~min}$. from start of observation, vapor pressure $657 \mathrm{~Pa}$, humidity 93\%. Bar is $200 \mu \mathrm{m}$.

\section{References:}

[1] A Schenkmayerová et al., Applied Biochemistry and Biotechnology 174 (5) (2014), p. 1834.

[2] V Neděla, et al., Nuclear Instrumentation and Methodology A 645 (2011), p. 79.

[3] E Tihlaříková, V Neděla and M Shiojiri, Microscopy and Microanalysis 19 (2013), p. 914.

[4] This work was supported by the Grant Agency of the Czech Republic: grant No. GA 14-22777S and Slovak Grant Agency for Science VEGA 1/0229/12 